\title{
Colangite esclerosante secundária em paciente com síndrome da imunodeficiência adquirida tratada com plastia do ducto hepático comum por via laparoscópica
}

\author{
Secondary sclerosing cholangitis in a patient with acquired immunodeficiency \\ syndrome treated by common hepatic duct \\ plasty by the laparoscopic route
}

\author{
Eduardo Crema ${ }^{1}$, Lara Beatriz Prata Ribeiro ${ }^{1}$, Fabrício Gomes da Silva ${ }^{1}$, \\ Ricardo Pastore ${ }^{1}$, Antônio Carlos Oliveira de Meneses $^{2}$ e Alex Augusto Silva ${ }^{1}$
}

\begin{abstract}
RESUMO
Relatamos o caso de um paciente com icterícia obstrutiva cuja causa era colangite esclerosante secundária à síndrome da imunodeficiência adquirida. Na colangiopatia relacionada à síndrome da imunodeficiência adquirida, os pacientes apresentam dor no quadrante superior direito ou epigástrico, febre, diarréia e alterações biliares características. $O$ paciente foi submetido à plastia transversa do ducto bepático comum por via laparoscópica.
\end{abstract}

Palavras-chaves: Colangite esclerosante. SIDA. Icterícia. Laparoscopia. Ducto hepático.

\begin{abstract}
We report the case of a patient with obstructive jaundice caused by sclerosing cholangitis secondary to acquired immunodeficiency syndrome. In acquired immunodeficiency syndrome-related cholangiopathy, patients present with right upper quadrant or epigastric pain, fever, diarrhea and characteristic biliary alterations. The patient was submitted to transverse plasty of the common hepatic duct by laparoscopic route.
\end{abstract}

Key-words: Sclerosing cholangitis. AIDS. Jaundice. Laparoscopy. Hepatic duct.

Doenças hepáticas, colecistite, principalmente acalculosa, e doenças do ducto biliar são descritas em pacientes com síndrome da imunodeficiência adquirida (SIDA) ${ }^{6}$. As alterações biliares características incluem estenose da papila, colangite esclerosante, estenose do ducto biliar extra-hepático e uma combinação desses achados ${ }^{4}$.

Embora a etiologia da SIDA relacionada à colangite esclerosante ainda não esteja clara, em grande parte dos casos investigados, infecções secundárias estão implicadas, sendo que, os agentes mais comumente identificados são citomegalovírus, criptosporídio $^{8}$ e microsporídio ${ }^{17}$.

Há poucos relatos na literatura sobre as anormalidades do trato biliar em pacientes com síndrome da imunodeficiência adquirida, principalmente, quando há necessidade de intervenção cirúrgica.

Descrevemos um paciente que, após 10 anos de diagnóstico de SIDA, desenvolveu colangite esclerosante e foi submetido à plastia transversa do ducto hepático comum por via laparoscópica.

\footnotetext{
1. Departamento de Cirurgia do Aparelho Digestivo da Faculdade de Medicina do Triângulo Mineiro, Uberaba, MG. 2. Laboratório de Anatomia Patológica e Citologia do Hospital Dr. Hélio Angotti, Uberaba, MG.

Endereço para correspondência: Dr. Eduardo Crema. Disciplina de Cirurgia do Aparelho Digestivo/FMTM. Rua Getúlio Guaritá s/n, 38025-440 Uberaba, MG, Brasil.

Tel: 5534 3318-5228.

e-mail: eduardocremafmtm@mednet.com.br

Recebido para publicação em 17/11/2004

Aceito em 18/6/2005
} 


\section{RELATO DO CASO}

Um homem de 42 anos, heterossexual, tabagista e etilista há 27 anos, ex-usuário de drogas, apresentou-se com icterícia, diarréia, fezes esbranquiçadas, urina de coloração escura, prurido por todo o corpo e perda de peso. Relatou que a icterícia surgira há 30 dias e por isso, o tratamento anti-retroviral (zidovudina, didanosina, nevirapina), que estava sendo usado há 18 meses, foi suspenso. Há 10 anos recebeu o diagnóstico de SIDA. Neste período, teve como intercorrências várias pneumonias bacterianas.

No exame físico, o paciente apresentou-se ictérico $(3+/ 4+)$, referiu dor à palpação no hipocôndrio direito e epigástrio, com fígado e baço não palpáveis e sem linfadenomegalia. Não apresentava antecedentes cirúrgicos e negou doença hepatobiliar prévia.

Os exames laboratoriais revelaram: número de linfócitos CD4 de $881 \times 10^{6} /$, carga viral de 2.209 cópias/mL, bilirrubina total de $23,12 \mathrm{mg} / \mathrm{dl}$, bilirrubina direta de $19,10 \mathrm{mg} / \mathrm{dl}$, fosfatase alcalina 1.355 U/, gama GT 1.498 U/, AST: 124 U/, ALT: 131 U/1, hemoglobina: $12 \mathrm{~g} / \mathrm{dl}$, leucócitos: $9,4 \times 10^{3} / \mathrm{mm}^{3}$ e plaquetas: $303 \times 10^{3} / \mathrm{mm}^{3}$. Ultrassonografia (US) abdominal revelou acentuada dilatação de vias biliares intra-hepáticas, vesícula biliar contraída e colédoco de calibre normal. A tomografia computadorizada (TC) do abdome total (Figura 1) mostrou fígado de dimensões aumentadas, acentuada dilatação de vias biliares intra-hepáticas, linfadenomegalia para-aórtica e pericaval; a vesícula biliar, o hepático comum e o colédoco não foram visualizados. A endoscopia digestiva alta não detectou alterações no esôfago, estômago, duodeno e papila de Vater. A colangiografia transparieto hepática (CTPH) evidenciou dilatação das vias biliares intra-hepáticas difusamente com interrupção da passagem do contraste no ducto hepático comum próximo à junção dos hepáticos.

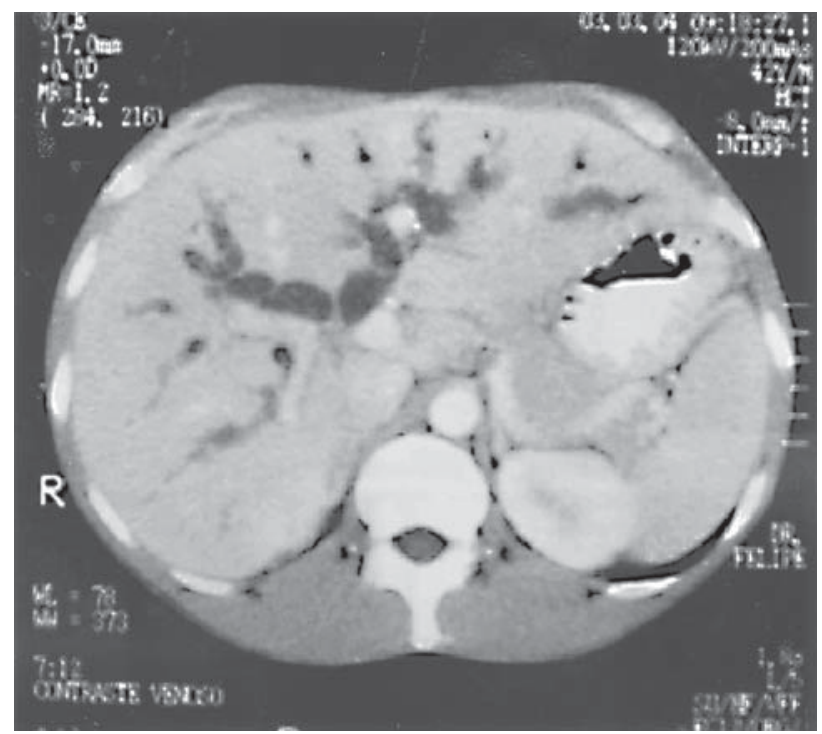

Figura 1 - Tomografia computadorizada de abdome com contraste venoso e oral que demonstra acentuada dilatação de vias biliares intra-bepáticas.
Após preparo nutricional enteral por uma semana e antibioticoterapia terapêutica com metronidazol $(1,5 \mathrm{~g} / \mathrm{dia})$ e gentamicina $(240 \mathrm{mg} /$ dia $)$, o paciente foi submetido à abordagem laparoscópica. Na exploração da cavidade abdominal, identificouse estreitamento focal de $0,3 \mathrm{~cm}$ de extensão no ducto hepático comum, dilatação do segmento proximal ao ducto (cerca de $1,5 \mathrm{~cm}$ de comprimento) e dilatação dos ductos hepáticos direito e esquerdo. A vesícula biliar e o colédoco encontravam-se normais e não havia presença de massa tumoral na região.

Foi realizada colangiografia per-operatória pelo ducto cístico que evidenciou colédoco normal, boa passagem do contraste pela papila duodenal e estenose focal de $0,3 \mathrm{~cm}$ no ducto hepático comum. Optou-se pela abertura do hepatocolédoco abaixo da zona de estreitamento onde se observou estenose puntiforme com mucosa normal macroscopicamente. Na face anterior $\mathrm{da}$ via biliar, realizou-se incisão longitudinal de cerca de $2 \mathrm{~cm}$ acometendo a região estenosada e retirou-se uma fita que, junto com o linfonodo cístico, foram enviados para estudo anatomopatológico de congelação. A biópsia revelou processo inflamatório inespecífico com presença de fibrose no segmento da via biliar e linfonodo sem presença de neoplasia. Optou-se então por realizar plastia na via biliar através de sutura transversal com pontos separados utilizando fio de prolene 3.0 e agulha de $2 \mathrm{~cm}$. Praticou-se a colecistectomia e drenagem externa da via biliar com dreno de Kehr exteriorizado pelo ducto cístico.

0 exame anatomopatológico, após fixação, demonstrou que o fragmento da via biliar apresentava tecido conjuntivo fibroso cicatricial com inflamação crônica inespecífica leve a moderada (Figuras 2 e 3). Neste exame, empregou-se coloração hematoxilina-eosina e Panótico. Observou-se também colecistite crônica moderada na vesícula biliar e que o linfonodo cístico apresentava histiocitose sinusal e hiperplasia leve, sendo que, as pesquisas de fungos e micobactérias resultaram negativas.

A evolução pós-operatória foi satisfatória até $05^{\circ} \mathrm{dia}$, momento em que o paciente apresentou quadro infeccioso e abscesso no flanco direito detectado pelo US e TC do abdome.

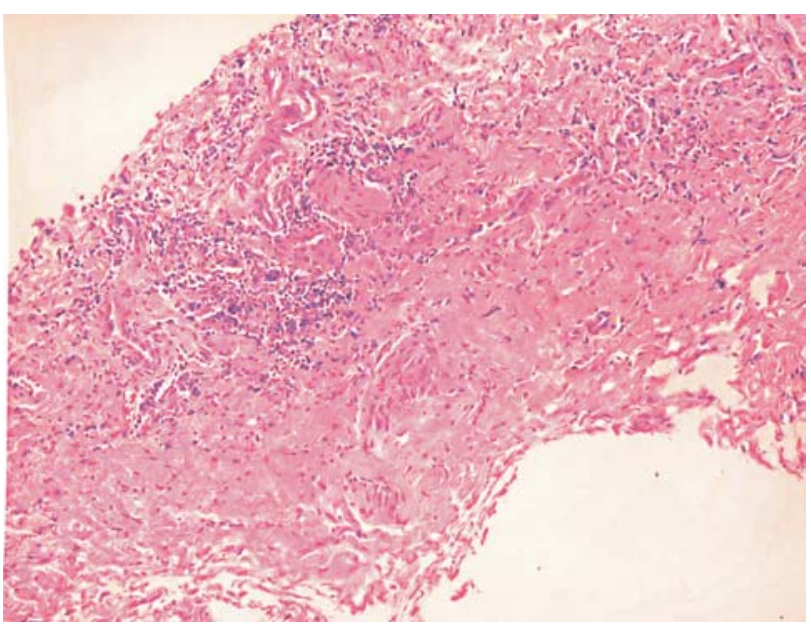

Figura 2 - Lâmina corada com hematoxilina-eosina mostrando colédoco com parede de tecido conjuntivo fibroso e com moderada infiltração de pequenos linfócitos. 


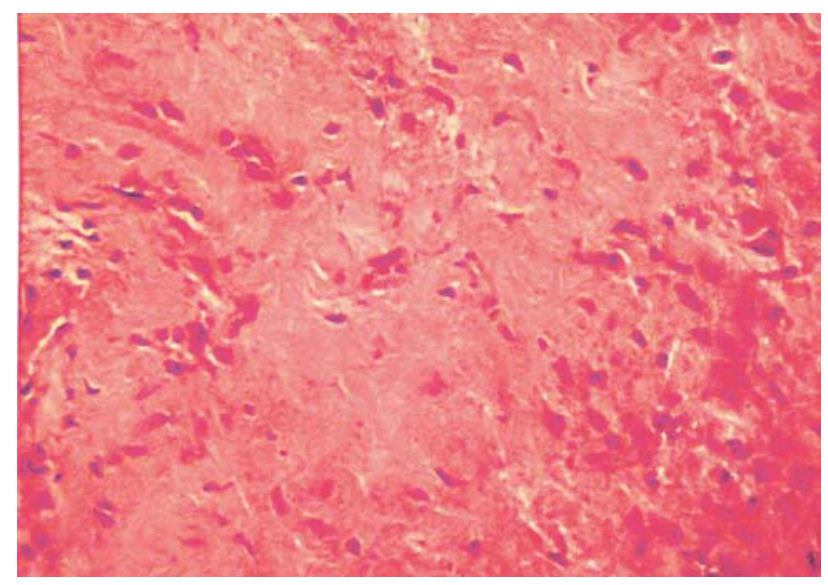

Figura 3 - Lâmina corada com bematoxilina-eosina evidenciando colédoco, em grande aumento, onde se nota a parede representada por tecido conjuntivo fibroso.

0 abscesso foi drenado por via percutânea com resolução clínica satisfatória. 0 ultrassom também mostrou que as vias biliares intrahepáticas já apresentavam calibre normal. A presença de Pseudomonas aeruginosa e de Acinetobacter calcoaceticcus foi detectada no $6^{\circ}$ dia de pós-operatório através de cultura da secreção biliar. A colangiografia realizada no mesmo dia demonstrou diminuição da dilatação intra-hepática, colédoco de calibre e contornos normais, boa passagem de contraste para o duodeno e ausência de extravasamento de contraste pela hepatorrafia.

0 paciente recebeu alta hospitalar no $12^{\circ}$ dia. 0 dreno de Kehr foi retirado no $47^{\circ}$ dia de pós-operatório após exame radiológico que mostrou vias biliares com calibre e permeabilidade normais (Figura 4). 0 esquema anti-retroviral (Biovir e Nelfinavir) foi introduzido 30 dias após a cirurgia. Após sete meses, o paciente encontra-se anictérico e com resultados laboratoriais normais.

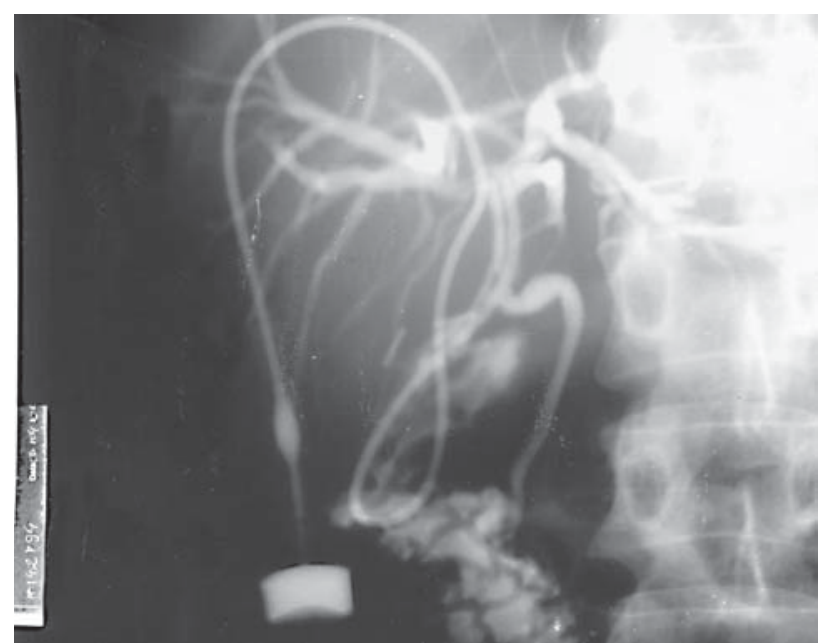

Figura 4 - Colangiografia realizada pelo dreno no $47^{\circ}$ dia de pósoperatório que mostra redução importante da dilatação de vias biliares intra-bepáticas com boa permeabilidade da via biliar extra-bepática.

\section{DISCUSSÃO}

Os pacientes com colangiopatia relacionada à SIDA queixam-se de dor abdominal no quadrante superior direito ou epigástrico e nas provas de função hepática que denotam obstrução apresentam resultados anormais ${ }^{1}$. 0 aumento mais expressivo é o da fosfatase alcalina ${ }^{248}$ cujo valor neste paciente foi de 11 vezes maior que o normal. Os pacientes também podem apresentar febre ${ }^{11}$ e diarréia ${ }^{69}$. Embora a icterícia seja incomum $^{67911}$, ela foi a manifestação clínica mais evidente neste paciente. Cello ${ }^{3}$ e Forbes cols ${ }^{5}$ encontraram icterícia presente em $15 \%$ de seus casos estudados, sendo que o diagnóstico da colangiopatia relacionada à SIDA baseou-se em achados radiográficos. Vinte de 26 pacientes (77\%) apresentaram resultados anormais na colangiografia endoscópica retrógrada (ERCP). Desses pacientes, 75\% tiveram alterações significativas no US ou TC, ou ambas ${ }^{3}$. Neste caso, o diagnóstico da colangiopatia foi suspeitado pela colangiografia transparieto hepática (CTPH).

A colangite esclerosante secundária caracteriza-se por estenoses focais e dilatações dos ductos biliares intra e extrahepáticos ${ }^{4}$. Seu diagnóstico é mais apropriado quando a dilatação e/ou estenose encontra-se na árvore biliar proximal $^{6}$. Neste paciente, a CTPH mostrou retenção do contraste no ducto hepático comum proximal; na abordagem laparoscópica evidenciou-se estenose focal de $3 \mathrm{~mm}$ no ducto hepático comum com dilatação dos ductos hepáticos direito e esquerdo e a colangiografia per-operatória descartou alterações do colédoco e da papila. Esses dados associados ao exame anatomo-patológico permitiram o diagnóstico de colangite esclerosante secundária. Nota-se que na colangite esclerosante primária o infiltrado inflamatório celular, encontrado ao redor do ducto biliar afetado, é rico em linfócitos T CD $4^{10}$, subpopulação especificamente afetada em pacientes com SIDA.

Quanto à terapêutica, neste caso foi necessária a abordagem cirúrgica para a drenagem biliar uma vez que a estenose se encontrava no terço proximal da árvore biliar. A cirurgia está indicada sempre que há associação da colangite com colecistite crônica ${ }^{11}$. Após a abordagem cirúrgica neste paciente, notou-se que no $12^{\circ}$ dia de pósoperatório os níveis de bilirrubina e fosfatase alcalina diminuíram 55\% e 71,5\%, respectivamente, em relação aos valores pré-operatórios.

Patógenos podem ser identificados em cerca de $75 \%$ dos casos de colangite em cultura da bile e amostras de fezes ou biópsias da ampola de Vater ou de outro lugar do trato gastrointestinal ${ }^{16}$. Neste paciente, 6 dias após a cirurgia, foram identificadas bactérias Gram negativas na cultura da bile. No exame histológico, foi encontrada inflamação crônica inespecífica do fragmento da via biliar. $\mathrm{Cello}^{4}$, ao avaliar biópsia da ampola de Vater, também encontrou em $55 \%$ dos seus pacientes alterações inflamatórias agudas e crônicas.

o diagnóstico e o tratamento das afecções biliares, que ocorrem em pacientes com SIDA, ainda são um desafio para a medicina. Relatamos uma abordagem minimamente invasiva para o tratamento definitivo da afecção biliar procurando melhor resultado pós-operatório pela utilização da técnica laparoscópica. 


\section{REFERÊNCIAS BIBLIOGRÁFICAS}

1. Bird GLA, Kennedy DH, Forrest JAH. AIDS-related cholangitis: diagnostic features and course in four patients. Scottish Medical Journal 40:53-54,1995.

2. Bonacini M. Hepatobiliary complications in patients with human immunodeficiency virus infection. The American Journal of Medicine 92:404-411,1992.

3. Cello JP. Acquired Immunodeficiency Syndrome Cholangiopathy: Spectrum of Disease. The American Journal of Medicine 86:539-546,1989.

4. Cello JP. Human Immunodeficiency Virus-Associated Biliary Tract Disease. Seminars in liver disease 12:213-218,1992.

5. Forbes A, Blanshard C, Gazzard B. Natural history of AIDS related sclerosing cholangitis: a study of 20 cases. Gut 34:116-121,1993.

6. Liu KJM, Atten MJ, Donahue PE. Cholestasis in Patients with Acquired Immunodeficiency Syndrome: A Surgeon's Perspective. The American Surgeon 63:519-524, 1997.
7. Pol S, Romana CA, Richard S, Amouyal P, Desportes-Livage I, Carnot F, Pays JF, Berthelot P. Microsporidia infection in patients with the human immunodeficiency virus and unexplained cholangitis. The New England Journal of Medicine 328:95-99,1993.

8. Roulot D, Valla D, Brun-Vezinet F, Rey M-A, Clavel F, Degott C, Guillan J, Verduron J, Rueff, Benhamou J-P. Cholangitis in the acquired immunodeficiency syndrome: report of two cases and review of the literature. Gut 28:1653-1660,1987.

9. Silva F, Boudghene F, Lecomte I, Delage Y, Grange J-D, Bigot J-M. Sonography in AIDS-related cholangitis: prevalence and cause of an echogenic nodule in the distal end of the common bile duct. American Journal of Roentgenology 160:1205-1207,1993.

10. Whiteside TL, Lasky S, Si L, Van Thiel DM. Immunologic analysis of mononuclear cells in liver tissue and blood of patients with primary sclerosing cholangitis. Hepatology 5:468-474,1985.

11. Wind P, Chevallier JM, Jones D, Frileux P, Cugnenc PH. Cholecystectomy for cholecystitis in patients with acquired immune deficiency syndrome. The American Journal of Surgery 168:244-246,1994. 